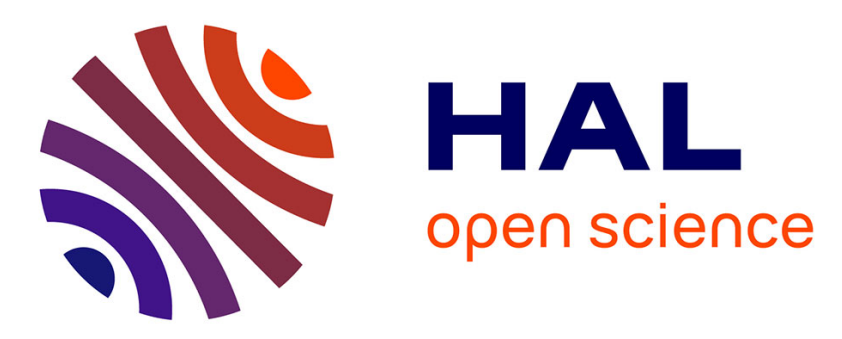

\title{
Kinetic modelling of the thermal decomposition of ettringite into metaettringite
}

Jérémie Pourchez, Françoise Valdivieso, Philippe Grosseau, Alexandre Govin, Bernard Guilhot

\section{- To cite this version:}

Jérémie Pourchez, Françoise Valdivieso, Philippe Grosseau, Alexandre Govin, Bernard Guilhot. Kinetic modelling of the thermal decomposition of ettringite into metaettringite. Cement and Concrete Research, 2006, 36 (11), pp.2054-2060. 10.1016/j.cemconres.2006.06.007 . emse-00449727

HAL Id: emse-00449727

https://hal-emse.ccsd.cnrs.fr/emse-00449727

Submitted on 19 Sep 2010

HAL is a multi-disciplinary open access archive for the deposit and dissemination of scientific research documents, whether they are published or not. The documents may come from teaching and research institutions in France or abroad, or from public or private research centers.
L'archive ouverte pluridisciplinaire $\mathbf{H A L}$, est destinée au dépôt et à la diffusion de documents scientifiques de niveau recherche, publiés ou non, émanant des établissements d'enseignement et de recherche français ou étrangers, des laboratoires publics ou privés. 


\section{Kinetic modelling of the thermal decomposition of ettringite into metaettringite}

J. Pourchez ${ }^{*}-$ F. Valdivieso-P. Grosseau -A. Govin-B. Guilhot

Ecole Nationale Supérieure des Mines de Saint-Etienne (ENSMSE-SPIN)

LPMG: process in granular media laboratory CNRS UMR 5148

158, cours Fauriel 42023 Saint-Etienne cedex 2 - France

* Corresponding author: Tel: (+33) 4774266 86; Fax: (+33) 4774996 94;

E-mail address: pourchez@emse.fr 


\section{AbSTRACT.}

Despite recent insights into thermal stability and decomposition mechanisms of ettringite, a lack of knowledge on nucleation and growth mechanisms of metaettringite remained. Therefore, a better understanding of the kinetic modelling of this heterogeneous reaction was proposed. Thanks to an experimental approach allowing to check the validity of kinetic assumptions (rate-determining step, expression of the rate as $\mathrm{d} \alpha / \mathrm{dt}=\mathrm{k} f(\alpha) \ldots$ ), a good agreement was found between the calculated and experimental $\alpha$ vs. $\mathrm{t}$ and $\mathrm{d} \alpha / \mathrm{dt}$ vs. $\mathrm{t}$ kinetic curves. The reaction area of the region in which the growth-limiting step occurs was also elucidated. Finally, we demonstrated that the rate-limiting step of the growth process did not follow perfectly an Arrhenius law in non isothermal conditions.

Keywords: ettringite, metaettringite, thermal decomposition, kinetic modelling.

\section{Introduction}

Ettringite is a common hydrated phase of Portland cement. The structure of this hydrous calcium-alumina-sulfate mineral is well-known [1]. Ettringite contains globally $32 \mathrm{H}_{2} \mathrm{O}$ molecules per formula unit (water contents are specified per six calcium ions). Even if the transformation of ettringite has been the subject of several studies, the mechanism and reaction kinetics of this transformation remains poorly understood. Nevertheless, recent works reported interesting data concerning the thermal stability of ettringite [2]. It was proved that ettringite was thermally unstable for temperature lower than $120^{\circ} \mathrm{C}$ (Figure 1). Depending on the temperature-humidity range, the ettringite decomposes to a product containing 10 to 13 $\mathrm{H}_{2} \mathrm{O}$ molecules per ettringite formula unit (Figure 2). Afterward, the structure of this partially deshydroxylated product, called metaettringite, was examined. It was found that the columnar structure of metaettringite is like ettringite, but with closer packing of columns in the a direction [3]. These authors precisely characterized the decomposition product, and rigorously 
described the reaction in terms of both temperature and water vapour partial pressures. Due to these reliable data, the kinetic modelling of ettringite decomposition becomes possible.

\section{Experimental procedures}

The reaction examined is the thermal decomposition of ettringite as the thermogram featured

in Figure 3. The experiments were conducted with a thermobalance (Setaram - ATG-DSC 111) under dynamic argon environment. The mass of sample was $20 \mathrm{mg}$. The temperature and the partial water vapour pressure represented key variables of the decomposition process. Although the water vapour pressure was not rigorously controlled, a very low water vapour pressure was maintained during the transformation owing to both the programmation temperature applied (a $50^{\circ} \mathrm{C}$ isothermal condition or a $0.5^{\circ} \cdot \mathrm{min}^{-1}$ heating rate), the dynamic argon environment and the low mass of sample introduced. The complete decomposition of ettringite at $50^{\circ} \mathrm{C}$ was attained for a 20 hours experiment, duration necessary to obtain the final thermogravimetry plateau (Figure 3). Thanks to data from Zhou et al shown in figure 2, we knew that the duration of the transformation is 8 hours for a water vapour pressure fixed at $6 \mathrm{~mm} \mathrm{Hg}$. This observation confirms that the water vapour pressure, not directly controlled, was very low and remained under $6 \mathrm{~mm} \mathrm{Hg}$.

To control perfectly the water content of the ettringite before the thermal decomposition, ettringite is stored in a drying oven at $35^{\circ} \mathrm{C}$. These storage conditions allow ettringite to lose two of its maximum $32 \mathrm{H}_{2} \mathrm{O}$ molecules. The loss of zeolitic water ("zeolitic" because the transformation is reversible), is always performed to maintain the water content per formula unit at $30 \mathrm{H}_{2} \mathrm{O}$ (noted $\mathrm{n}=30$ ) at the beginning of each experiment.

Finally, the degree of conversion of the reaction $\alpha(t)$ was simply expressed by the mean of the mass loss at time $t$, and the mass loss when the transformation was considered as finished. The thermogravimetry curves were converted into the kinetic curves $\alpha(t)$ using Eq 1 . It was observed that the water content of the initial ettringite can change owing to the zeolitic 
behavior of a part of water. As a result, the final mass loss $(\Delta \mathrm{m} \mathrm{f})$ which was indicated by a thermogravimetry plateau, varied between $25 \%$ and $25.2 \%$.

Equation 1: Expression of the degree of conversion by means of the mass loss at time $t$ (noted $\Delta \mathrm{m}(\mathrm{t})$ ), and the mass loss when the transformation is considered as finished (noted $\Delta \mathrm{m} \mathrm{f}$ )

$$
\alpha(t)=\frac{\Delta m(t)}{\Delta m f}
$$

\section{Theorical approach of the kinetic modelling}

In numerous kinetic studies on solid-state reactions, in isothermal or non isothermal conditions, the reaction rate is given by $\mathrm{Eq} 2$ in which $\mathrm{A}$ is called the preexponential factor, $\mathrm{E}$ is the activation energy and $f(\alpha)$ is an analytical function.

Equation 2: Rate of reaction expressed by means of an Arrhenius law and a Sharp law

$$
\frac{d \alpha}{d t}=A \exp \left(\frac{-\mathrm{E}}{\mathrm{RT}}\right) \times f(\alpha)
$$

Several $f(\alpha)$ functions can be used, depending on the shape of the grains and the step controlling the growth process, the most commonly used functions being detailed in [4]. However Eq 2 is only valid in a few cases: the nucleation process (respectively the growth process) is instantaneous, which means that the model describes only the growth process (respectively the nucleation process). Typically, Eq 2 is not valid when nucleation and growth processes are in competition. Moreover, Eq 2 implies that the rate is controlled by a step following the Arrhenius law, which is not always the case (for example, when an adsorption step is involved, following the Langmuir isotherm). For these reasons, we prefer a more general expression of the rate, given by Eq 3 [5-6], in which $\phi$ is a rate per unit area (mol.s ${ }^{1} . \mathrm{m}^{-2}$ ) and depends on the nature of the rate-determining step (interface step or diffusion) and is independent on time in isothermal and isobaric conditions. $\mathrm{E}(\mathrm{t})\left(\mathrm{m}^{2} \cdot \mathrm{mol}^{-1}\right)$ corresponds to the extent of the reaction zone where the rate-limiting step occurs. Eq 3 is interesting since it 
only assumes the existence of the rate-limiting step for the growth, but no additional assumption is made concerning the nature nor the localization of this step.

Equation 3: Rate of reaction expressed by means of $\mathrm{E}$ and $\phi$ functions.

$$
\frac{d \alpha}{d t}=\Phi(\mathrm{T}, \mathrm{P}) \mathrm{E}(\mathrm{t}, \Phi, \gamma)
$$

The validity of Eq 3 can be verified experimentally, as shown later (part 5). Moreover, this approach was successfully used in the kinetic modelling of many heterogeneous reactions such as the decomposition of $\mathrm{CaCO}_{3}$ [7], the reduction of $\mathrm{U}_{3} \mathrm{O}_{8}$ into $\mathrm{UO}_{2}$ [8-9], the deshydroxylation of kaolinite [10] or the decomposition of $\mathrm{CeOHCO}_{3}[11]$.

\section{Investigation of the thermal decomposition}

Beforehand the kinetic modelling, it was essential to precisely characterize the investigated reaction, in order to prove that the ettringite decomposition occurs with the formation of a new solid phase. Thus, two ways are possible: to characterize the decomposition product (and to prove that it is a new solid phase), or to calculate the variance of the system (and if the system is divariant, it means that there is only one solid phase which is non-stoechiometric and so the approach described previously is not valid). In the thermogramm shown in figure 3 , we notice that the investigated transformation of the ettringite induced a weight loss of $25 \%$ which corresponds to a final weight loss of water of about 17.5 moles per mol of ettringite. As the initial water content of ettringite is close to 30 moles per mol of ettringite (noted $n=30$ ), we find a degradation product which contains beetwen 12 and 13 moles of water per mol of decomposition product. This result is perfectly coherent with the decomposition product obtained in the same decomposition conditions by Zhou et al. So, thanks to these data, we can say that the examined transformation of ettringite gives rise a new solid phase (called metaettringite and isostructural with despujolsite minerals, collectively termed dfs phases) containing 12 to $13 \mathrm{H}_{2} \mathrm{O}$ per ettringite formula unit [3]. Thus, we can write the investigated reaction : 
ettringite $(n=30)=$ metaettringite $($ dfs-structured phase, $n=12)+18 \mathrm{H}_{2} \mathrm{O}$

\section{Experimental validation of $\operatorname{Eq} 3$ : " $\phi E$ test"}

The considered approach is based on the existence of a rate-limiting step for the growth process. A growth mechanism is generally composed of several elementary steps involving reaction intermediates (adsorbed species, point defects). One of these steps can be assumed to be rate-determining, which implies that the system is in a steady-state. This validation of the steady state assumption was conducted by showing that the reaction rates obtained by two different experimental methods remained strictly proportional during the whole reaction. We have used simultaneous thermogravimetry and calorimetry and we succeeded to demonstrate that a scale factor can be found to superpose the rate of weight loss (DTG) and the heat flow signal (Figure 4). As a result the steady state assumption is verified.

Then, to apply Eq 3 we must also demonstrate that the $\phi$ function is not dependent on the time of reaction. This is possible owing to sudden changes in temperature (or partial pressures) during the transformation [5,6,9-11]. Indeed, a first experiment was performed in fixed temperature conditions (noted T1). At time t1, the temperature was suddenly changed from $\mathrm{T} 1$ to $\mathrm{T} 2$. In a second experiment, the same change (from $\mathrm{T} 1$ to $\mathrm{T} 2$ ) was conducted at time $\mathrm{t} 2$, different from $\mathrm{t} 1$. Let us consider the ratio of the rates before (noted $\mathrm{Rb}$ ) and after (noted $\mathrm{Ra}$ ) the sudden change. Only if Eq 3 can be applied, it is easy to see that the ratios of the rates before and after the sudden change at $\mathrm{t} 1$ and $\mathrm{t} 2$ must be equal (since the $\mathrm{E}(\mathrm{t})$ function is eliminated in the ratios). This procedure is featured in Figure 5. This experimental method was performed for the transformation of ettringite with a sudden change of $\mathrm{T} 1=50^{\circ} \mathrm{C}$ to $\mathrm{T} 2=$ $60^{\circ} \mathrm{C}$, at $\mathrm{t} 1$ corresponding to $\alpha=0.3$ and $\mathrm{t} 2$ corresponding to $\alpha=0.55$ (Figure 6 ). The ratio of the rates before and after this sudden change of temperature is $1.93 \pm 0.01$ for $\alpha=0.3$, and $1.91 \pm 0.01$ for $\alpha=0.55$. Consequently Eq 3 can be applied to investigate the decomposition of ettringite into metaettringite. 


\section{Determination of $\mathbf{E}(\mathbf{t})$}

The function $E(t)$ represents the extent of the reaction zone where the rate-limiting step occurs. It depends on several factors: the initial geometry and size of the ettringite grains, the nature of the process which is involved (instantaneous nucleation or growth, competition between both processes), the nature of the region in which the rate-limiting step of the growth process occurs (interfacial step or diffusion step), and finally the direction of the development of the metaettringite (internal or external development).

The nature of the process is the key to determine the complexity of the E function. A complex case appears when nucleation and growth are competitive processes. On the contrary, if nucleation or growth occur with a supposed infinite rate, the modelling is easier [5-6]. In this last case, one process is instantaneous and $\mathrm{E}(\mathrm{t})$ is fully determined by means of the fractional conversion, independently to the way chosen to reach this value of $\alpha$. In others words, if the physico-chemical stresses (temperature and water vapour pressure) are fixed, the degree of conversion fully determines the rate of reaction and the $\mathrm{E}$ function can be written as $\mathrm{E}(\alpha)$. The experimental method used to verify this point consisted at first in beginning an isothermal experiment at $50^{\circ} \mathrm{C}$ and performing a sudden change of temperature from $50^{\circ} \mathrm{C}$ to $60^{\circ} \mathrm{C}$. Then, the curve $d \alpha /$ dt vs. $\alpha$ obtained after the sudden change is compared to a curve obtained from an isothermal transformation at $60^{\circ} \mathrm{C}$. Results are illustrated in figure 7 . The curves are superimposed after the temperature change, which means that the E function is fully determined by the degree of conversion. Therefore, we can say that either the nucleation or the growth process is instantaneous during the decomposition of ettringite into metaettringite.

To determine the E function, experiments were performed in isothermal condition. As we proved that nucleation (or growth) is instantaneous, the rate of reaction can be expressed by the Eq 4 (in which $\mathrm{k}$ may depend on temperature and partial pressure of gases, thus $\mathrm{k}$ is a constant in isobaric and isothermal conditions). 
Equation 4: Rate of reaction in isothermal and isobaric conditions ( $\mathrm{k}$ is a constant)

$$
\frac{d \alpha}{d t}=k \times f(\alpha)
$$

The principle is then to plot d $\alpha / d t$ vs $f(\alpha)$ using the classical $f(\alpha)$ functions [4] in order to check if one of them could fit the experimental curves. If it is the case, the curve d $\alpha / d t$ vs $f(\alpha)$ obtained must be linear. Even if a bias is observed for $\alpha$ lower than 0.1 , the best function found is $f(\alpha)=(1-\alpha)^{1 / 2}$ (Figure 8). This geometrical model corresponds to the following assumptions (all the factors defining the E function are featured in figure 9):

$>$ a cylindrical shape of the grains (it is well-known that ettringite particles are needleshaped [1])

the nucleation of metaettringite is instantaneous (i.e. entire surfaces of ettringite are very rapidly covered with a thin layer of metaettringite)

the metaettringite grows inward the starting grains

the rate-limiting step of growth is located at the internal interface

\section{Variations of the $\phi$ function with temperature}

Concerning the determination of the $\phi$ function, the first stage consisted in verifying if the Arrhenius law could be applied to the investigated decomposition. If the Arrhenius law is valid, then the reaction rate can be expressed by Eq 5 and the curve $\ln (f(\alpha))$ vs $1 /$ T must be linear (Eq 6).

Equation 5: Rate of reaction if the $\phi$ function follows an Arrhenius law

$$
\frac{d \alpha}{d t}=A \exp \left(\frac{-\mathrm{E}_{\mathrm{a}}}{\mathrm{RT}}\right) \times(1-\alpha)^{\frac{1}{2}}
$$


Equation 6: Expression which must be valid if we apply an Arrhenius law

$$
\ln \left(\frac{\frac{d \alpha}{d t}}{(1-\alpha)^{\frac{1}{2}}}\right)=\ln (A)-\frac{\mathrm{E}_{\mathrm{a}}}{\mathrm{RT}}
$$

An experiment in non isothermal condition was performed with a temperature programmation of $0.5^{\circ} \cdot \mathrm{min}^{-1}$. Between $20^{\circ} \mathrm{C}$ and $100^{\circ} \mathrm{C}$, we doubtlessly notice that the curve $\ln (\mathrm{f}(\alpha)) \mathrm{vs} 1 / \mathrm{T}$ is not linear (Figure 10). Therefore, we can conclude that the decomposition of ettringite into metaettringite does not follow an Arrhenius law in non isothermal conditions, between $20^{\circ} \mathrm{C}$ and $100^{\circ} \mathrm{C}$. However, even if an Arrhenius law is not strictly correct, in a restricted range of temperature this law appears as a satisfactory approximation as shown in Figure 12. The variations of $\phi(\mathrm{T})$ have been obtained experimentally in the temperature range $55^{\circ} \mathrm{C}-70^{\circ} \mathrm{C}$, using again temperature jumps. In that case, temperature changes from $\mathrm{T}_{0}\left(50^{\circ} \mathrm{C}\right)$ to different values of $\mathrm{T}$, have been performed at a given fractional conversion $\alpha(\alpha=0.55)$, the ratio of the rates being then equal to $\phi(\mathrm{T}) / \phi\left(\mathrm{T}_{0}\right)$ (see Figure 11). The variations of $\phi$ with temperature $\mathrm{T}$ are given in Figure 12, the experimental data were fitted using an Arrhenius law, according to Eq 7 (continuous line in Figure 12).

Equation 7: Expression using an Arrhenius law in order to fit the experimental data (Figure 12)

$$
\frac{\phi(T)}{\phi\left(T_{0}\right)}=\frac{\exp \left(-\frac{\mathrm{E}_{\mathrm{a}}}{\mathrm{RT}}\right)}{\exp \left(-\frac{\mathrm{E}_{\mathrm{a}}}{\mathrm{R} T_{0}}\right)}
$$

The agreement between Eq 7 and the experimental data is correct, which means that an Arrhenius law is a good approximation for the $\phi$ function in the restricted range of temperature $55^{\circ} \mathrm{C}-70^{\circ} \mathrm{C}$. The apparent activation energy can be estimated: it is equal to 
$1.7 \mathrm{~kJ} \mathrm{~mol}^{-1}$. Then theoretical curves $\alpha(\mathrm{t})$ and $\mathrm{d} \alpha / \mathrm{dt}(\mathrm{t})$ can be calculated, and compared to the experimental ones. Figure 13 shows a good agreement between these curves.

\section{Conclusions}

To complete recent insights into thermal stability and decomposition mechanisms, this paper proposed a kinetic modelling of the decomposition of ettringite into metaettringite, leading to an expression of the reaction rate which allows to fit satisfactorily the experimental curves d $\alpha /$ dt vs $\alpha$. The transformation of ettringite needles occurs by instantaneous nucleation of metaettringite. The growth of metaettringite appears to be internal and the rate-limiting step of growth is located at the internal interface (between the two solid phases). Concerning the effect of temperature on the rate, we proved that the decomposition of ettringite did not follow an Arrhenius law in the general case. Nevertheless, in a restricted range of temperature $\left(55^{\circ} \mathrm{C}\right.$ $-70^{\circ} \mathrm{C}$ ), we have shown that an Arrhenius law appears to be a good approximation.

\section{Acknowledgements}

The authors would like to acknowledge the support of the Lafarge company concerning the ettringite synthesis. 


\section{References}

[1] A.E. MOORE, H.F.W. TAYLOR, Crystal structure of ettringite, Acta Crystallogr.. B26 (1970) 386-393.

[2] Q. ZHOU and F.P. GLASSER, Thermal stability and decomposition mechanisms of ettringite at $<120^{\circ} \mathrm{C}$, Cem. Concr. Res. 31 (2001) 1333-1339.

[3] Q. ZHOU, E.E. LACHOWSKI, F.P. GLASSER, Metaettringitte, a decomposition product of ettringite, Cem. Concr. Res. 34 (2004) 703-710.

[4] A.K. GALWAY and N.E. BROWN, Thermal decomposition of ionic solids, Elsevier (1999).

[5] M. SOUSTELLE and M. PIJOLAT, Experimental methods useful in the kinetic modelling of heterogenous reactions, Solid State Ionics. 95 (1997) 33-40.

[6] M. SOUSTELLE, Modélisation macroscopique des transformations physico-chimiques, Ed Masson, Paris, (1990).

[7] V. BOUINEAU, M. PIJOLAT, M. SOUSTELLE, Characterisation of the chemical reactivity of $\mathrm{CaCO}_{3}$ powder for its decomposition, Journal of the European ceramic society. 18 (1998) 1319-1324.

[8] M. PIJOLAT, C. BRUN, F. VALDIVIESO, M. SOUSTELLE, Reduction of uranium oxide $\mathrm{U}_{3} \mathrm{O}_{8}$ to $\mathrm{UO}_{2}$ by hydrogen. Solid State Ionics. 101-103 (1997) 931-935. 
[9] S. PERRIN, M. PIJOLAT, F. VALDIVIESO, M. SOUSTELLE, Kinetic study of the effect of a sudden change in temperature during the reduction of $\mathrm{U}_{3} \mathrm{O}_{8}$ into $\mathrm{UO}_{2}$ by hydrogen. Solid State Ionics. 141-142 (2001) 109-115.

[10] K. NAHDI, S. PERRIN, M. PIJOLAT, F. ROUQUEROL, N. ARIGUIB, N. AYADI, Nucleation and anisotropic growth model for isothermal kaolinite dehydroxylation under controlled water vapour pressure. Physical Chemistry Chemical Physics., 4 (2002) 1972-1977.

[11] J.P. VIRICELLE, M. PIJOLAT, M. SOUSTELLE, J. Chem. Soc. Faraday Trans. 91 (24) (1995) 4437. 
Figure 1

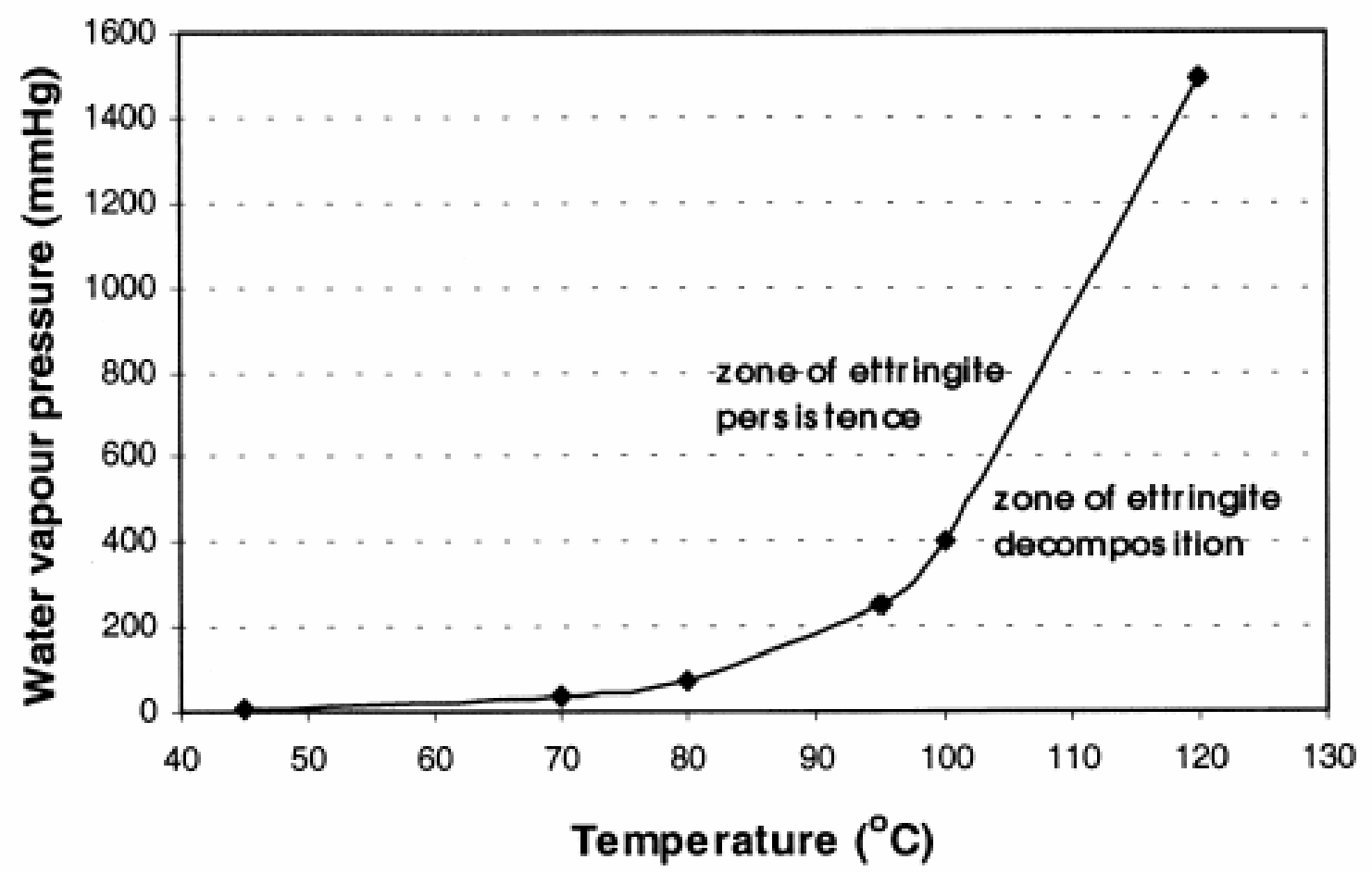


Figure 1 Data for monotropic decomposition of ettringite showing convergence of weight loss on a product containing $10-13 \mathrm{H}_{2} \mathrm{O}$ from Zhou et al [2]

J. Pourchez * -F. Valdivieso-P. Grosseau - A. Govin-B. Guilhot 
Figure 2

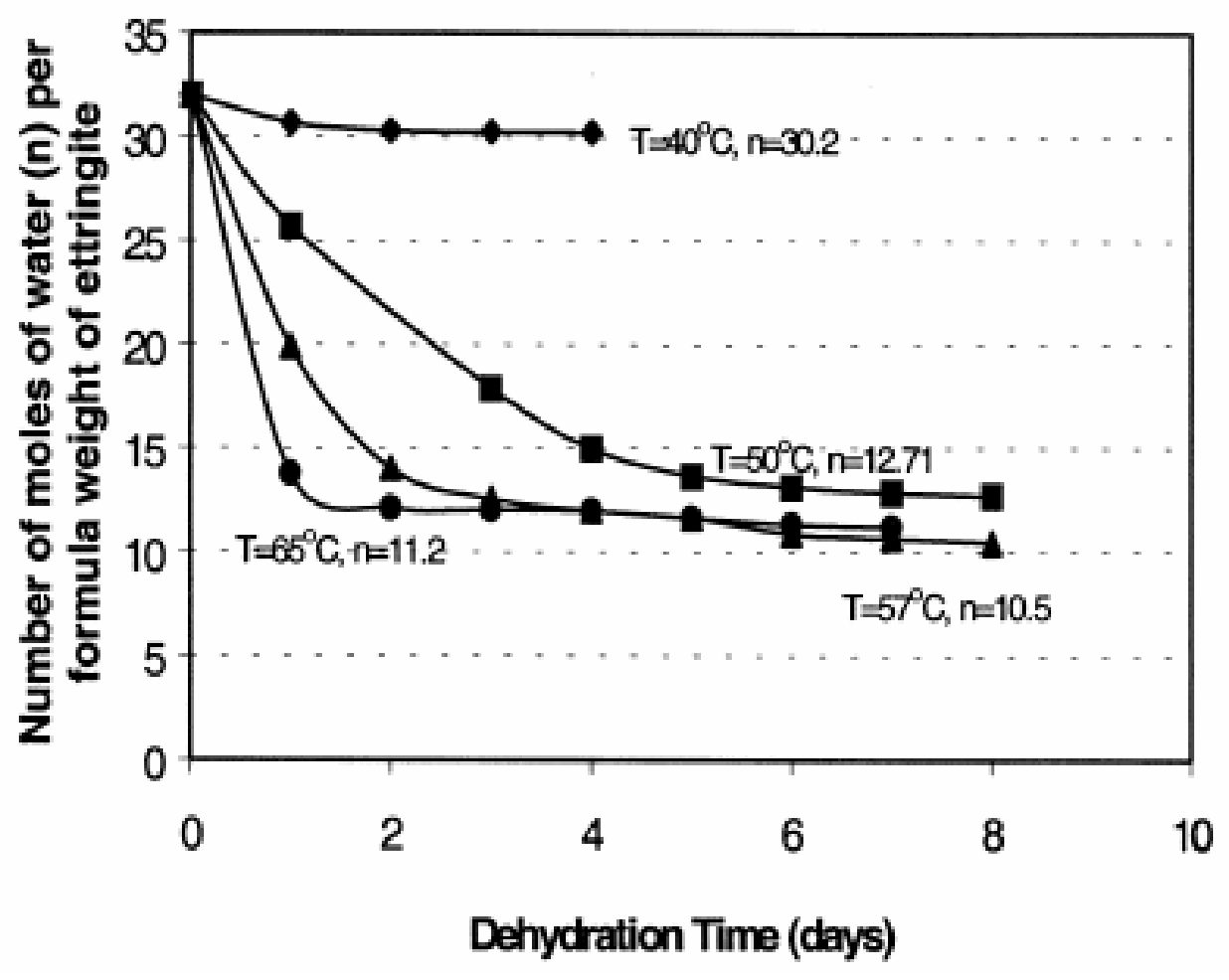


Figure 2 Static dehydration curves for ettringite as a function of time and temperature on isobar at $\mathrm{P}_{\mathrm{H} 2 \mathrm{O}}=6 \mathrm{mmHg}$ from Zhou et al [3]

J. Pourchez * -F. Valdivieso-P. Grosseau - A. Govin-B. Guilhot 
Figure 3

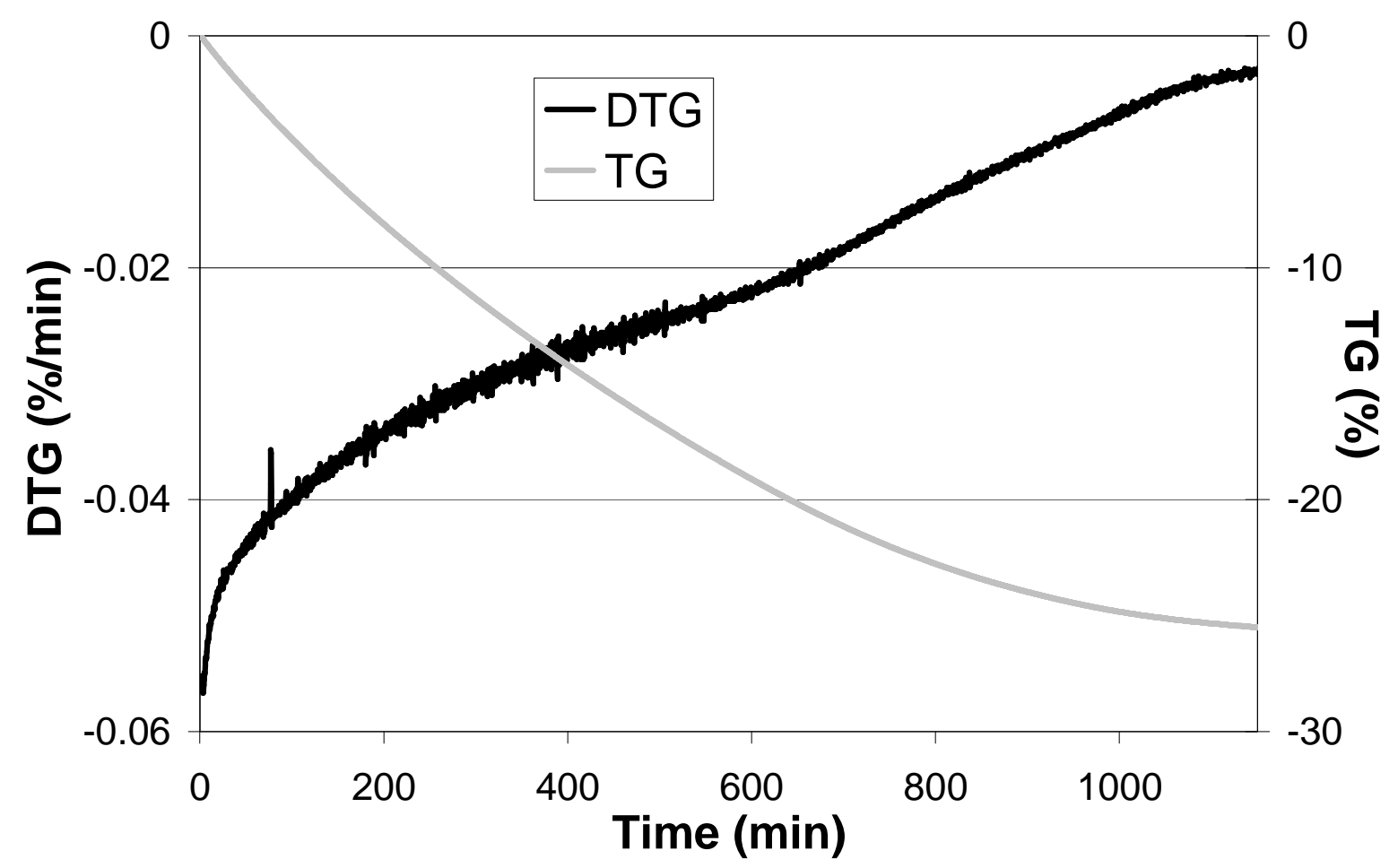


Figure 3 Thermogram of ettringite decomposition in isothermal condition $\left(\mathrm{T}=50^{\circ} \mathrm{C}\right.$ in $\operatorname{argon}$ environment)

J. Pourchez * - F. Valdivieso-P. Grosseau - A. Govin - B. Guilhot 
Figure 4

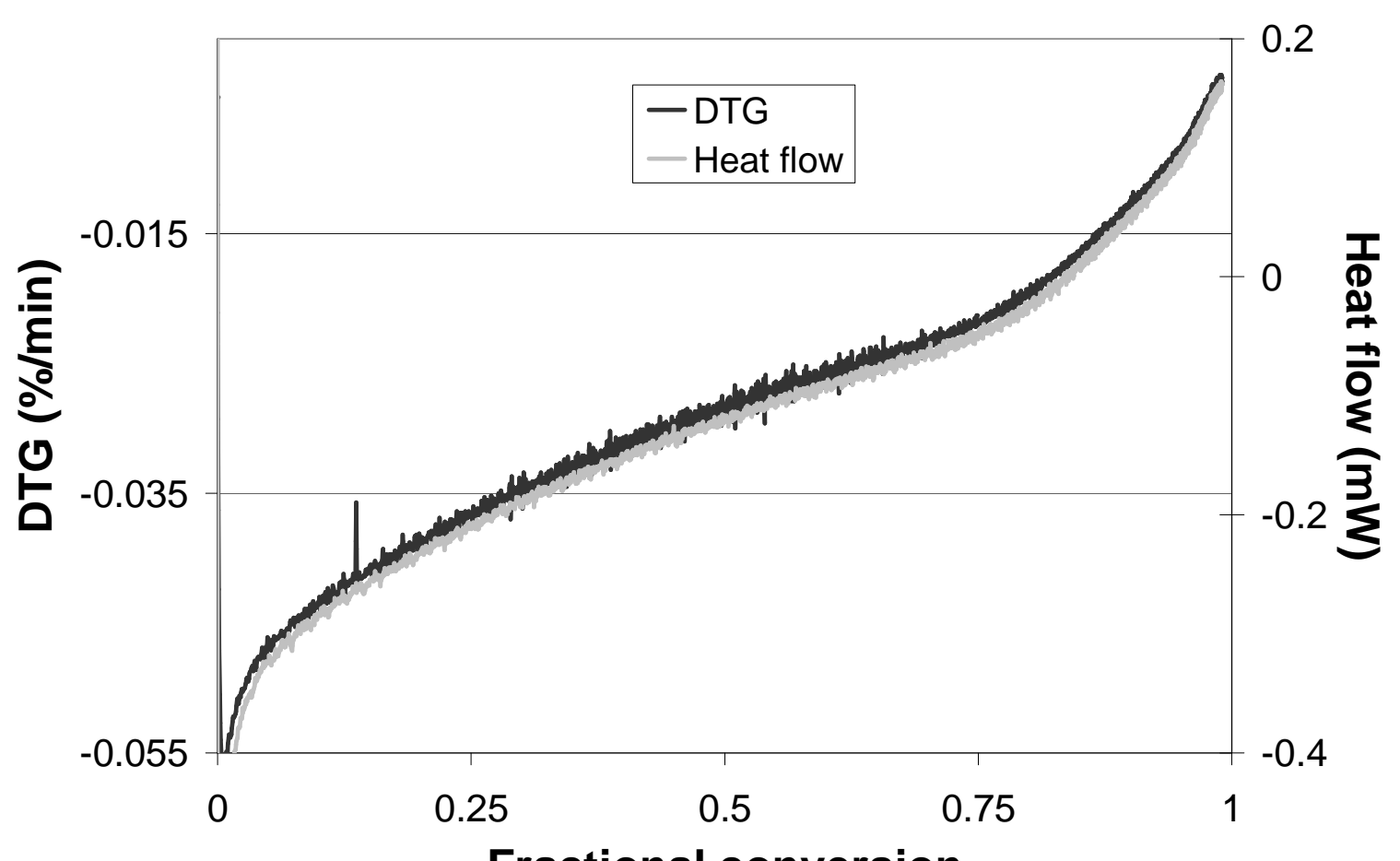

Fractional conversion 
Figure 4 Validation of the steady state assumption $\left(\mathrm{T}=50^{\circ} \mathrm{C}\right.$ in argon environment $)$ J. Pourchez * - F. Valdivieso-P. Grosseau - A. Govin-B. Guilhot 
Figure 5

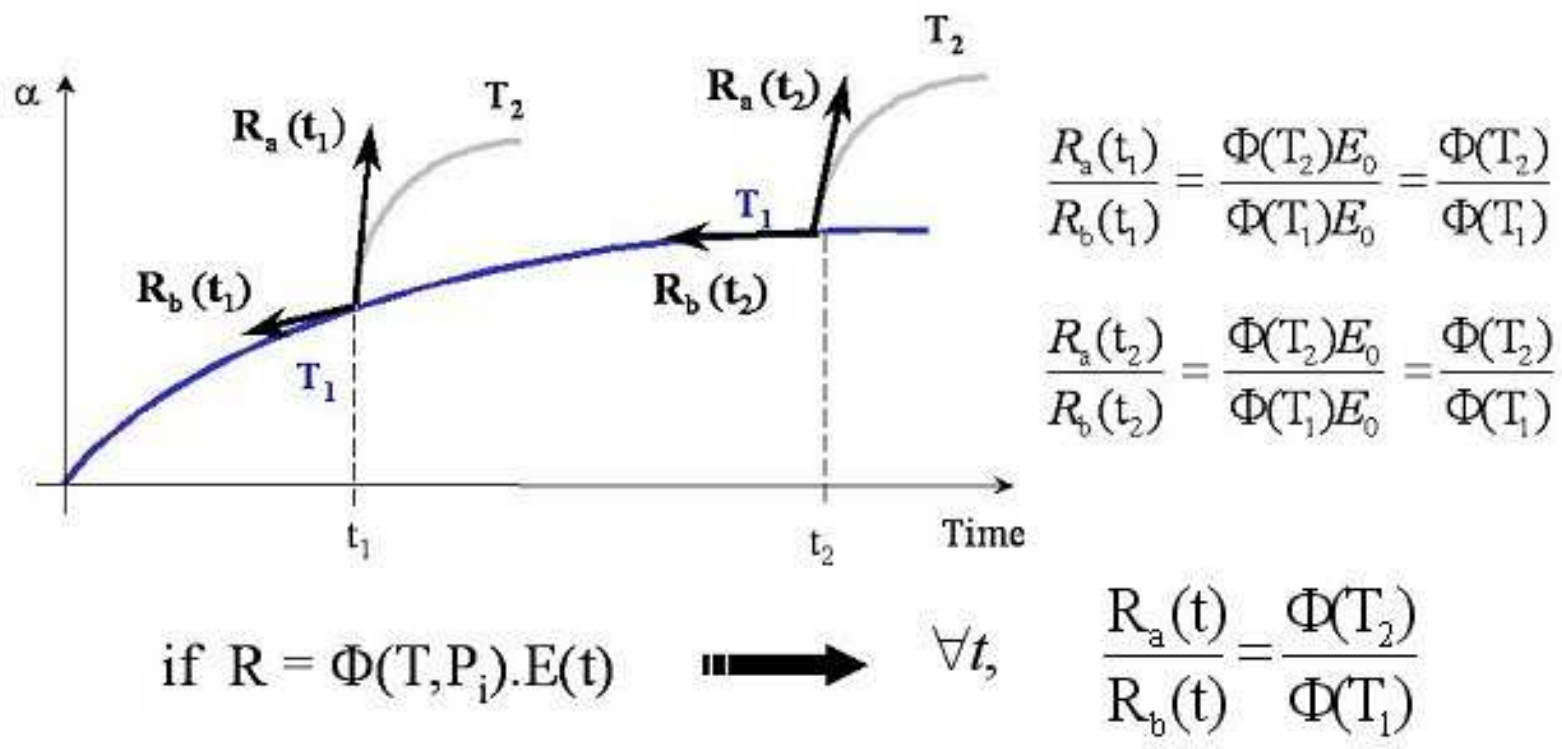


Figure 5 Principle of the experimental procedure based on the sudden change of temperature to demonstrate that the $\phi$ function is not dependent on the time of reaction J. Pourchez * - F. Valdivieso-P. Grosseau - A. Govin-B. Guilhot 
Figure 6

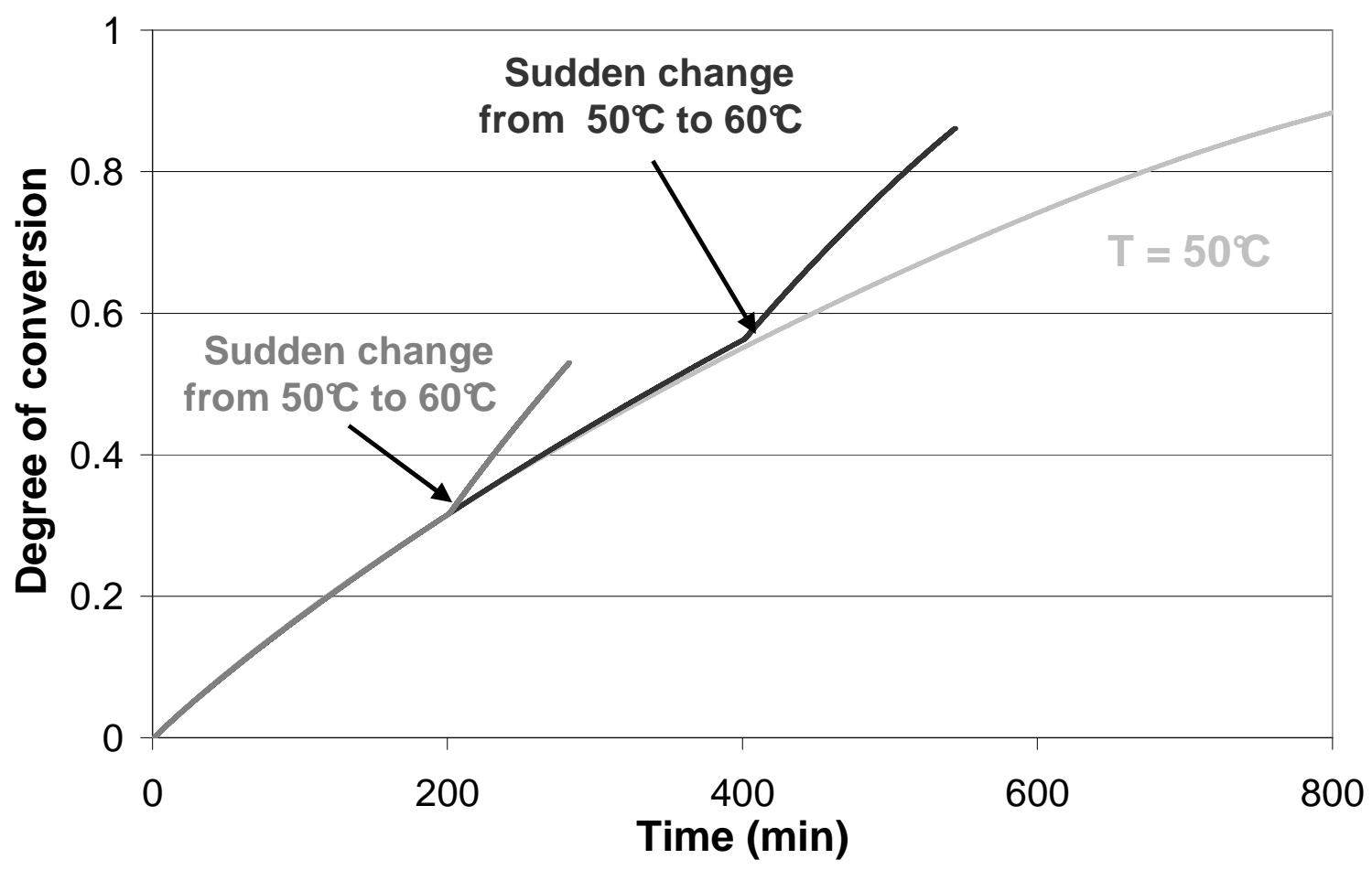


Figure 6 Decomposition of ettringite with sudden change from $50^{\circ} \mathrm{C}$ to $60^{\circ} \mathrm{C}$ : validation of $\mathrm{Eq}$ 3 , the $\phi$ function is not dependent on the time of reaction J. Pourchez * - F. Valdivieso-P. Grosseau - A. Govin-B. Guilhot 
Figure 7

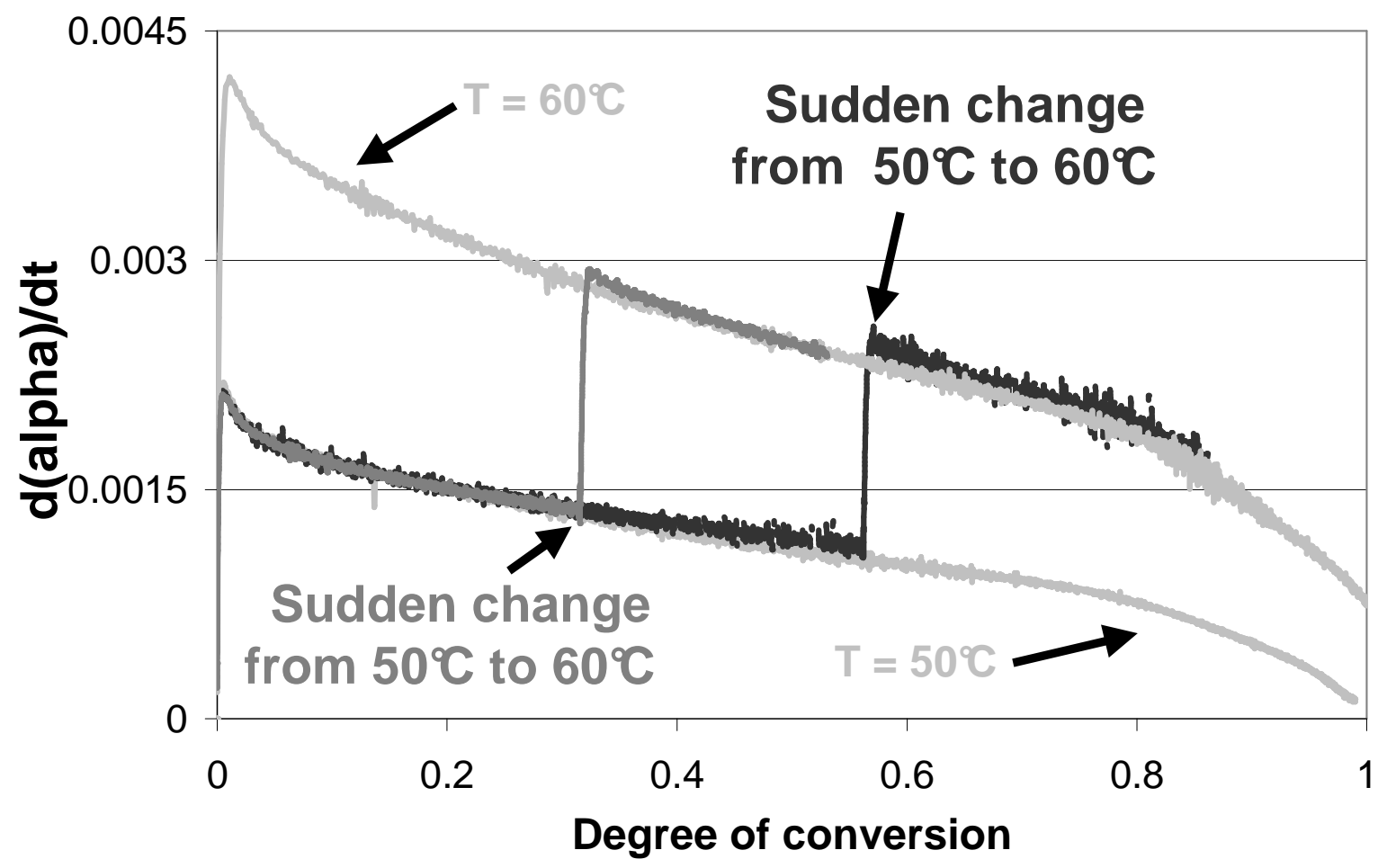


Figure 7 Decomposition of ettringite with sudden change from $50^{\circ} \mathrm{C}$ to $60^{\circ} \mathrm{C}$ : validation of $\mathrm{Eq}$ 4, the E function only depends on $\alpha$

J. Pourchez * - F. Valdivieso-P. Grosseau - A. Govin-B. Guilhot 
Figure 8

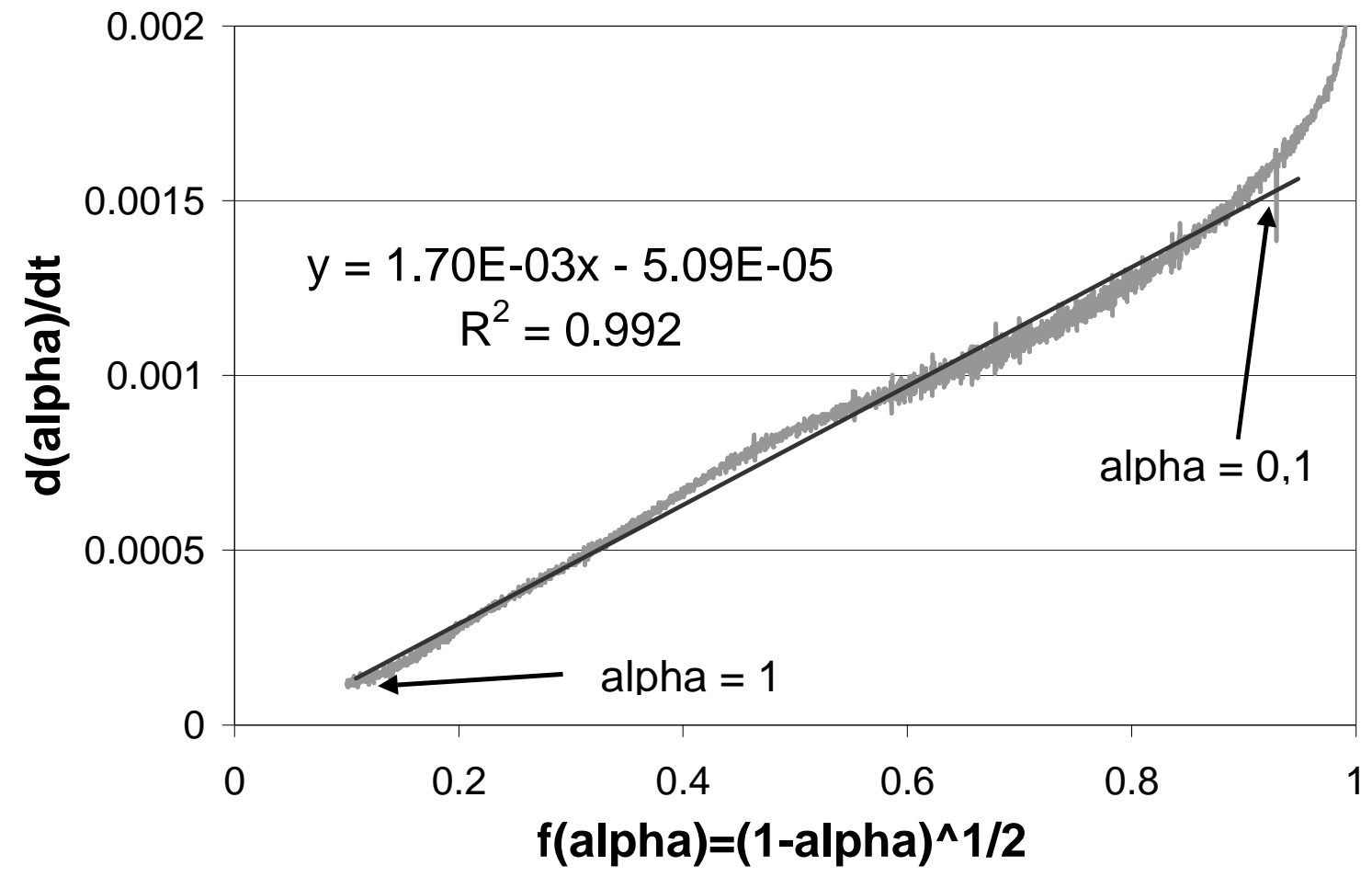


Figure 8 Validation of the expression of the reaction rate $: E(\alpha)=(1-\alpha)^{1 / 2}$

J. Pourchez * -F. Valdivieso-P. Grosseau - A. Govin-B. Guilhot 
Figure 9

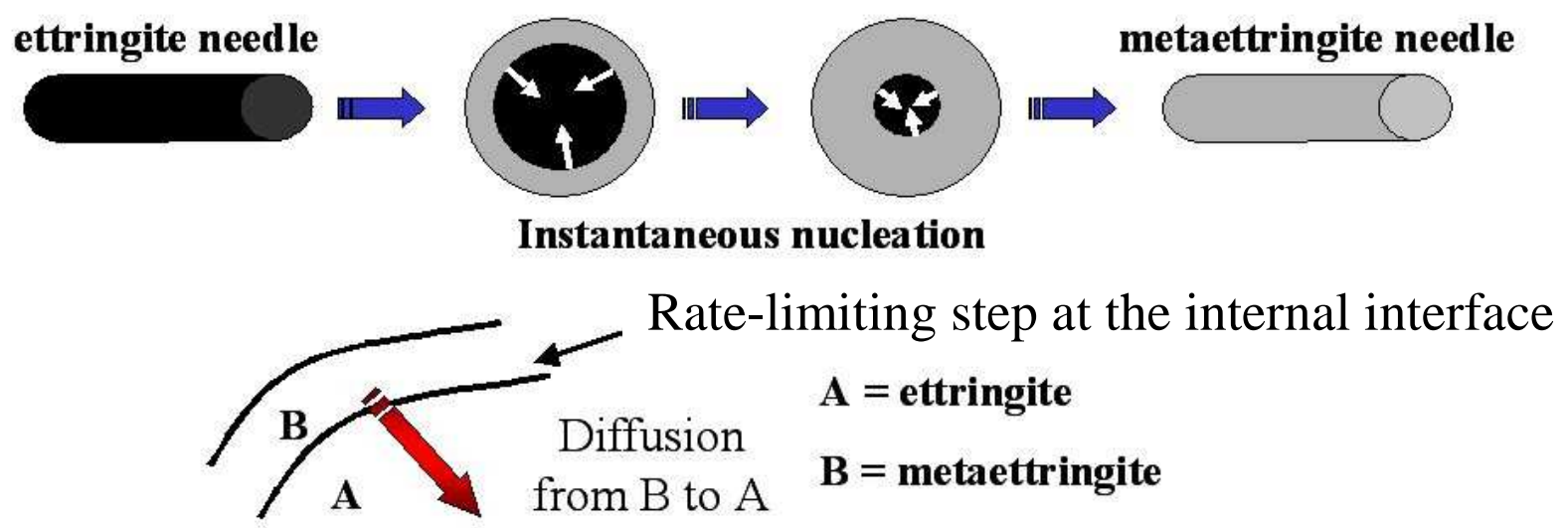


Figure 9 Assumptions corresponding to the E function

J. Pourchez * -F. Valdivieso-P. Grosseau - A. Govin-B. Guilhot 
Figure 10

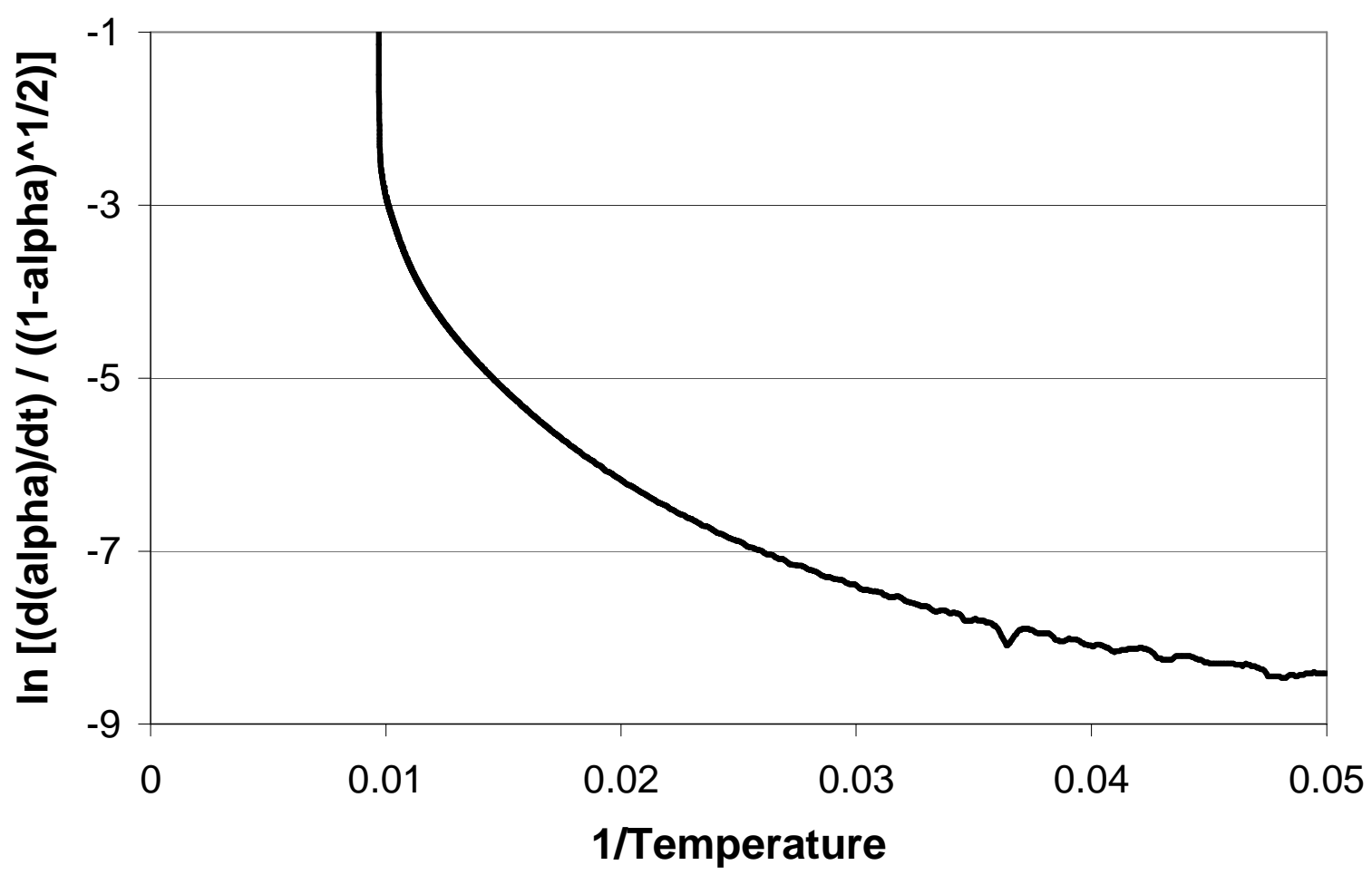


Figure 10 Verification of the validity of the Arrhenius law

J. Pourchez * -F. Valdivieso-P. Grosseau - A. Govin-B. Guilhot 
Figure 11

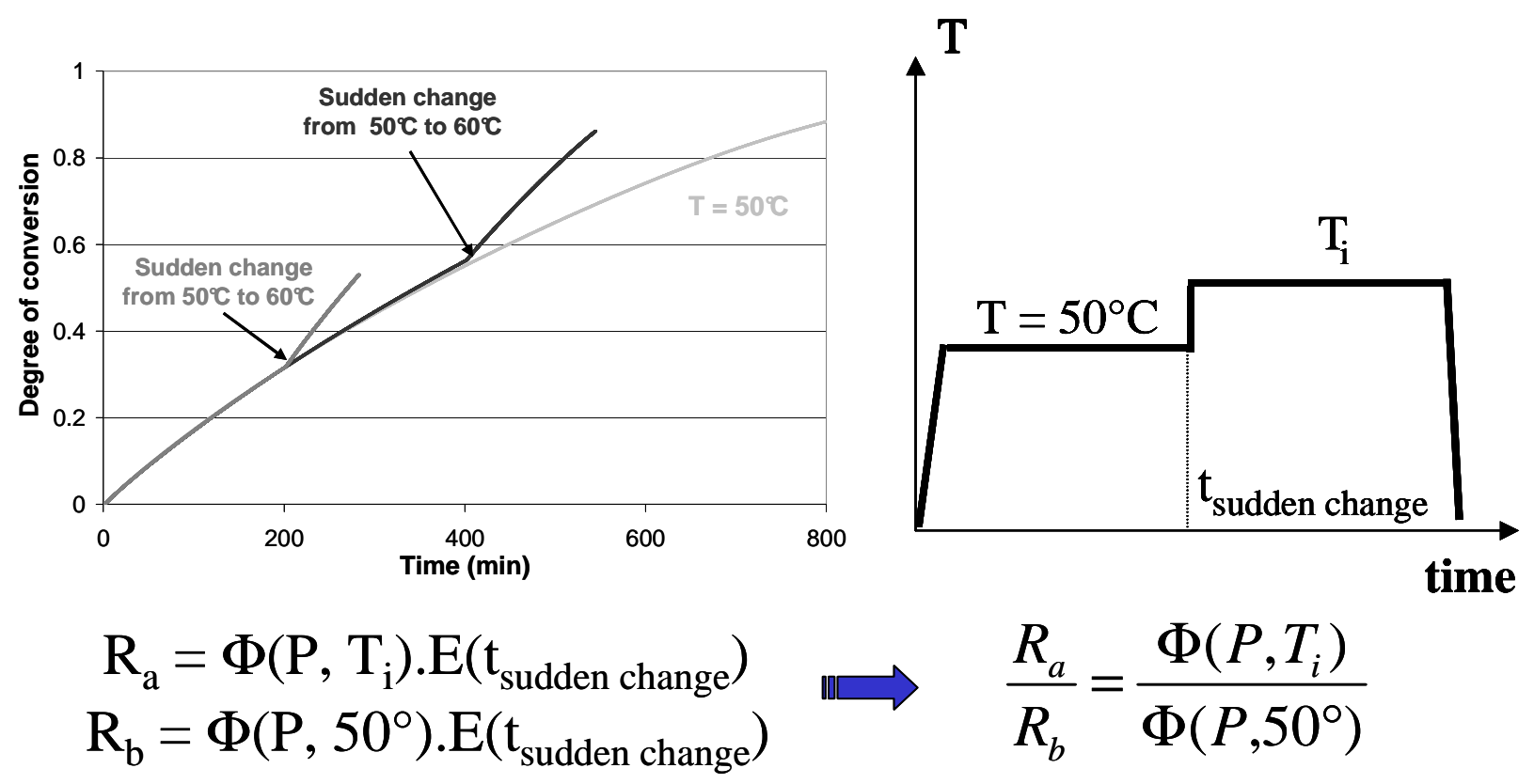


Figure 11 Principle of the experimental procedure based on the sudden change of temperature to determine the variations of $\phi$ function with temperature

J. Pourchez * - F. Valdivieso-P. Grosseau - A. Govin - B. Guilhot 
Figure 12

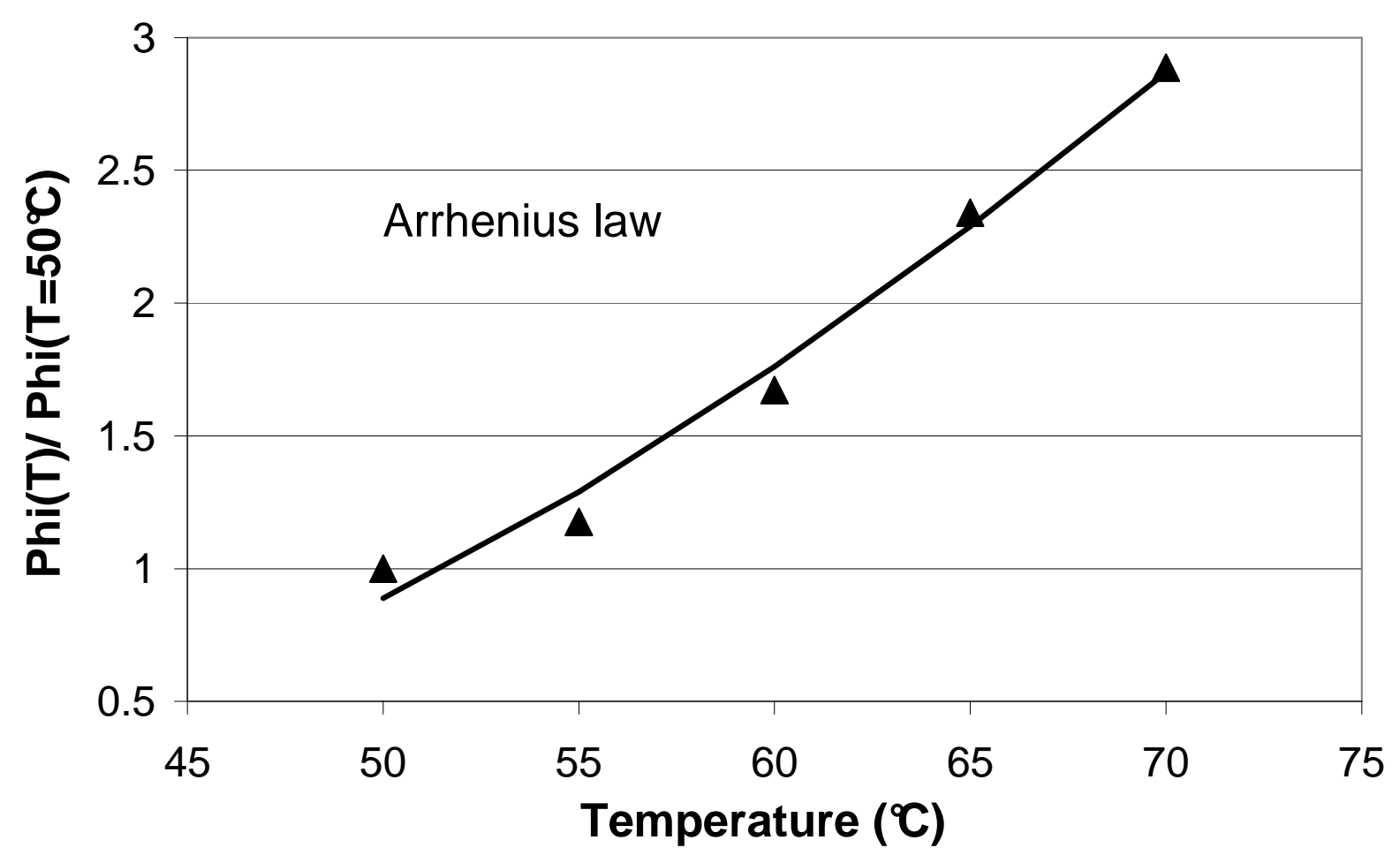


Figure 12 Experimental variations of $\phi(\mathrm{T})$ and validation of the Arrhenius law in a restricted temperature range

J. Pourchez * - F. Valdivieso-P. Grosseau - A. Govin - B. Guilhot 
Figure 13

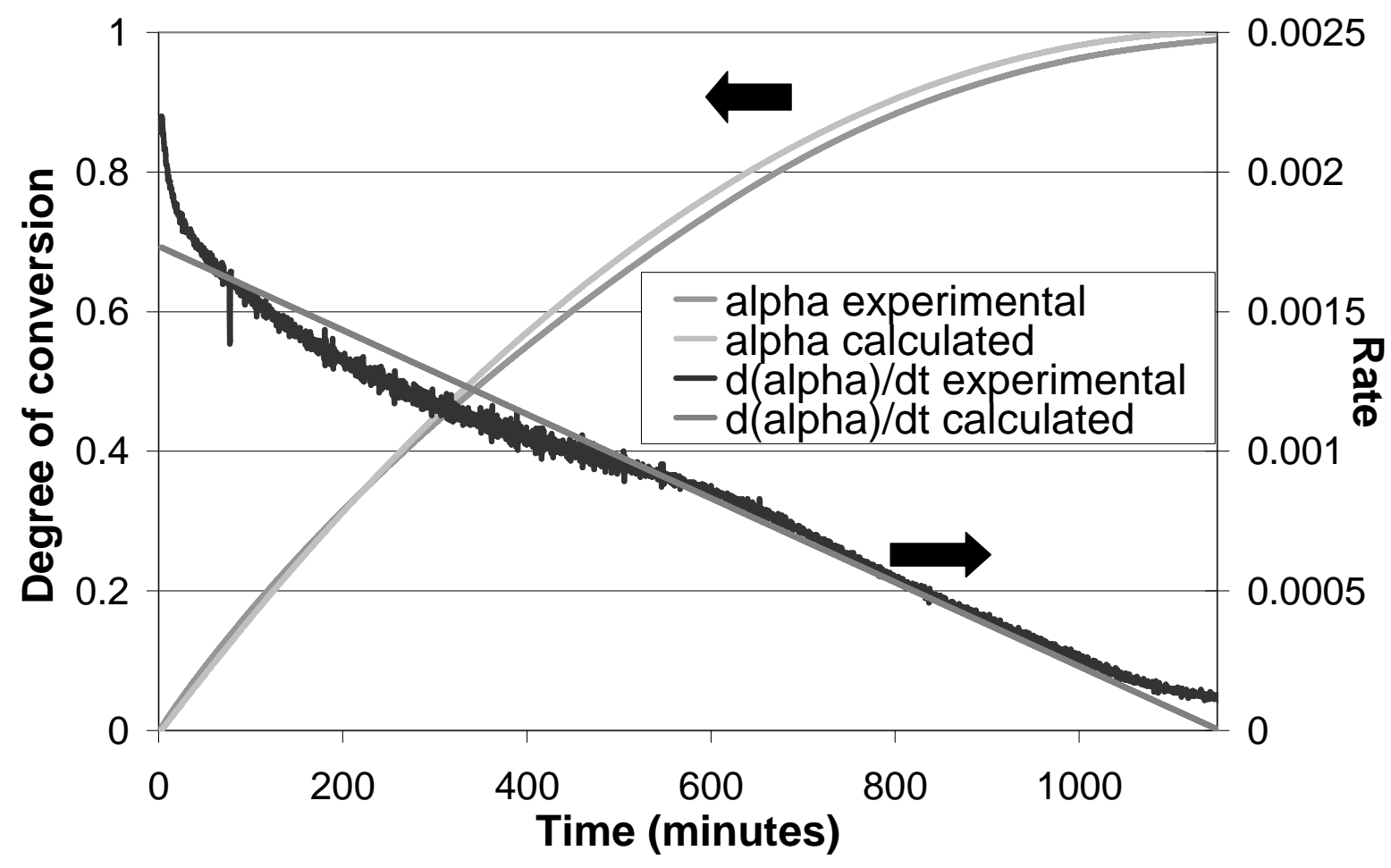


Figure 13 Good agreement between experimental and calculated kinetic curves for the isothermal decomposition of ettringite into metaettringite

J. Pourchez * - F. Valdivieso-P. Grosseau - A. Govin - B. Guilhot 


\section{Captions}

Fig 1 Data for monotropic decomposition of ettringite showing convergence of weight loss on a product containing 10-13 $\mathrm{H}_{2} \mathrm{O}$ from Zhou et al [2]

Fig 2 Static dehydration curves for ettringite as a function of time and temperature on isobar at $\mathrm{P}_{\mathrm{H} 2 \mathrm{O}}=6 \mathrm{mmHg}$ from Zhou et al [3]

Fig 3 Thermogram of ettringite decomposition in isothermal condition $\left(\mathrm{T}=50^{\circ} \mathrm{C}\right)$

Fig 4 Validation of the steady state assumption $\left(\mathrm{T}=50^{\circ} \mathrm{C}\right.$ in $\operatorname{argon}$ environment $)$

Fig 5 Principle of the experimental procedure based on the sudden change of temperature to demonstrate that the $\phi$ function is not dependent on the time of reaction

Fig 6 Decomposition of ettringite with sudden change from $50^{\circ} \mathrm{C}$ to $60^{\circ} \mathrm{C}$ : validation of $\mathrm{Eq} 3$, the $\phi$ function is not dependent on the time of reaction

Fig 7 Decomposition of ettringite with sudden change from $50^{\circ} \mathrm{C}$ to $60^{\circ} \mathrm{C}$ : validation of $\mathrm{Eq} 4$, the E function only depends on $\alpha$

Fig 8 Validation of the expression of the reaction rate $: E(\alpha)=(1-\alpha)^{1 / 2}$

Fig 9 Assumptions corresponding to the E function

Fig 10 Verification of the validity of the Arrhenius law

Fig 11 Principle of the experimental procedure based on the sudden change of temperature to determine the variations of $\phi$ function with temperature

Fig 12 Experimental variations of $\phi(\mathrm{T})$ and validation of the Arrhenius law in a restricted temperature range

Fig 13 Good agreement between experimental and calculated kinetic curves for the isothermal decomposition of ettringite into metaettringite 